\title{
Detroit dining
}

\section{Something for everyone}

\author{
by William P. Kane
}

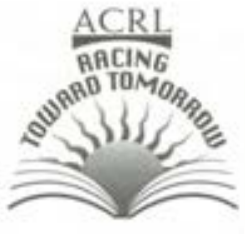

Since you're coming to Detroit for the ACRL National Conference April 8-11, 1999, and since, as your Mom might say, "Ya gotta eat," we offer this quick tour of the area's finest restaurants for your consideration (and temptation)

It may be that most people, when they think about Detroit, don't think about food or restaurants or fine dining--usually it's cars, music, or sports. However, the truth is, Detroit has lots of nice places where you can meet with friends and colleagues over a delicious and either quick or relaxed meal. It's also true that, in Detroit like most other cities, it helps if you know where you're going.

Detroit's a big town, with plenty of great restaurants throughout the entire city and its suburbs, but this guide highlights those you're most likely to stumble across as you navigate the city in relation to the conference schedule. Keep in mind that it's always a good idea to call in advance to confirm hours and get directions.

\section{Best of the best}

Detroit has a number of signature restaurants, where locals tend to go to celebrate a special occasion, such as an anniversary, a promotion, or just the weekend. These downtown spots celebrate the best of what the city has to offer: great food, sterling service, and an eclectic and charming mix of flavors and faces. Though they may not be cheap, in Detroit you don't get cheated.

The Whitney, 4421 Woodward, Detroit; (313) 832-5700; lunch, Monday-Friday, dinner daily, brunch Sunday; average entrée: $\$ 24$. Reservations recommended.

You simply cannot go wrong at the Whitney-where you can eat and feel like a king from the wine list to the salads and steaks and from the chops and the seafood to the desserts- the Whitney is where you want to be for any special meal.

A former lumber baron's home just up Woodward Avenue from downtown in the city's Cultural Center, the beautiful rooms in this gorgeously restored Victorian mansion are quite elegant and opulent, yet cozy and quiet. But the best part is the food, of course: try the roast duck breast fanned on a plate punctuated by plump raspberries. But save room for dessert, or take it upstairs to the third-floor bar to enjoy some soothing sounds with your soothing drink. A great place to close the deal or just unwind.

The Rattlesnake Club, 300 River Place, Detroit; (313) 567-4400; lunch, Monday-Friday, dinner, Monday-Saturday; average entrée: \$20. Reservations recommended.

\section{About the author}

William P. Kane cochairs ACRI's National Conference Local Arrangements Subrommittee and is regional sales manager for Blackwell's Book Services, e-mail: william kane Oblackwell com 
A beautiful place in an upscale downtown area along the Detroit River waterfront, the Rattlesnake offers seasonally fresh American dishes, divine desserts, a lovely martini bar, and a great wine list. The attentive staff serves the city's suits a number of grilled fish dishes, steaks and chops, as well as imaginative dishes like lake perch sautéed with citrus, capers, sweet peppers, and thyme. The setting is airy and sophisticated, with massive flower arrangements and contemporary art in a room with windows on two sides. A friendly, efficient, top-tier place.

Duet, 3711 Woodward, Detroit; (313) 831-3838; lunch, Monday-Friday, dinner, Monday-Saturday; average entrée: \$25. Reservations recommended.

This is a new addition to the city's top restaurants, and part of an ambitious Orchestra Place campus, which includes performing arts spaces, classrooms, administrative offices, and such. Indeed, it's a theatrical restaurant, with its raised burgundy banquettes and fabric-covered ceilings-elegant, but not clubby. The menu is ambitious, the food is good, and the presentation is stunning. Some recommendations: the seared salmon, the spicy duck wontons served with orange sauce and pineapple salsa, and the wild mushroom tart. The

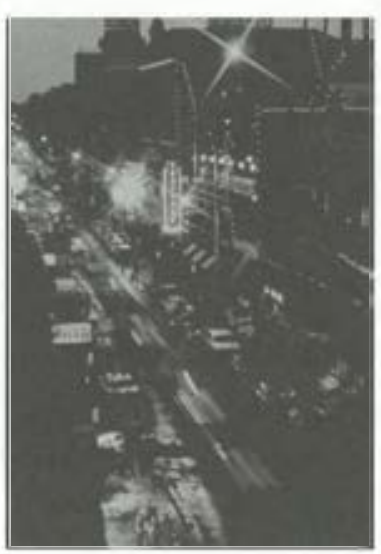

Greektown nightlife round of croquet on the nearby indoor/outdoor courts.

Opus One, 565 E. Larned, Detroit; (313) 961-7766; lunch, Monday-Friday, dinner, Monday-Saturday; average entrée: \$25. Reservations recommended.

Downtown's handsomest restaurant, lavished with etched glass and marble. A completely upscale approach and a kitchen that makes virtually everything from scratch. The menu changes regularly but seasonally includes such dishes as medallions of veal with Madeira sauce, rack of lamb, seafood en croute, and melange of lobster tail, rock shrimp, and seafood over angel hair pasta in a phyllo vase. Not to mention a pastry cart that is hard to resist.

The Grill Room (in the Ritz Carlton Hotel), 300 Towne Center Drive, Dearborn; (313) 441-2100; lunch and dinner daily; average entrée: \$31. Reservations recommended,

Refined and elegant, the Grill is in annual contention as the best restaurant in Michigan. The delicately prepared Dover sole with whole crawfish and basil noodles is expertly presented. Desserts will remind you that food and art are sometimes interchangeable. This is the kind of a place where you can take your time and savor every course.

Duet salad is dressed in a wonderful raspberry vinaigrette. There are not many tables, and they're usually all accounted for, so be sure to call ahead. Stay for the live cabaret music in the bar.

Baron's Steakhouse, 1000 River Place (in the River Place Hotel), Detroit; (313) 2594855; lunch, Monday-Friday, dinner, Monday-Saturday; average entrée: \$25. Reservations recommended.

A steakhouse with big portions of big Midwestern steaks with big river views. An à la carte menu also includes such dishes as grilled salmon, scampi atop fettuccine, and a mixed grill of filet mignon, grouper and game hen. Famous Detroit faces, automotive and political, gaze down from the walls. The kind of place that typifies the "power lunch," you'll leave too full to seriously consider a

\section{Greektown}

This strip of restaurants and bars in downthentic Greek cuisine, a place where every few minutes you can hear a waiter's exultant "Opa!" Just a couple PeopleMover stops from the Convention Center, Greektown's the kind of a place where an out-of-towner can cruise up and down the block for a bit, checking on the posted menus before deciding they're all good, they're all open (even on Sundays), and they're all reasonably priced. It's a great spot to come after dinner, too, since there are plenty of nice pastry and coffee shops to satisfy your sweet tooth or just to scratch that people-watching itch. There must be ten Greek restaurants in just a few blocks, and the locals all seem to have town Detroit is famous, naturally, for its au- 
identified their favorites; meanwhile, though, Greektown does offer more than just lamb chops and moussaka, a couple of other ethnic flavors are represented by the restaurants listed below.

Fishbone's Rhythm Kitchen Café, 400 Monroe, Detroit; (313) 965-4600; lunch and dinner daily; average entrée: $\$ 10$.

Fun, jumping, and kind of loud - a Cajun haven offering chicken and sausage sauce $\mathrm{pi}$ quant, drenched whiskey ribs, smoked Cajun salmon, oysters, peel-and-eat shrimp, and mussels. You have a hankering for some spicy fried alligator? No problem. Be sure to grab a faux Mardis Gras necklace on your way in or out, and don't forget to check out "the world's tallest indoor waterfall" in the adjacent office complex.

Blue Nile, 508 Monroe, Detroit; (313) 964-6699; dinner daily; average entrée: $\$ 13$. Reservations recommended.

Traditional Ethiopian-meaning the tables and chairs are just 18 inches off the floor and your (meat or vegetable) stew is served in a spongy bread called injera, which doubles as your utensil. Pieces of bread are simply torn off and used to scoop up the fare. A highly unusual dining experience, with seconds and thirds as part of the deal. It's out of the ordinary, but delicious and fun.

Loco Bar \& Grill, 454 E Lafayette, Detroit; (313) 965-3737; lunch and dinner daily; average entrée: $\$ 9$.

A Tex-Mex cowboy joint with fake ponyhair-covered booths, great selection of hot sauces and beers, enchiladas, quesadillas, and chunky salsa. On weekends, there's usually a fun live band in the adjacent bar. Good bar food at family prices.

\section{Theater district}

Detroit's downtown renaissance includes the full-scale restoration of several once- and again-grand theatres and movie houses, including the Fox, the State, and the Detroit Opera House. With major acts appearing throughout the city nightly, the strip of Woodward Avenue just a few blocks away from the Convention Center, downtown bustles with ticket-holders looking for a bite to eat before and after the show.

Tres Vite, 2203 Woodward, Detroit; (313) 964-4144; call for dinner hours; average entrée: \$18. Reservations recommended.
The urban cafe setting in the Fox Theatre building is quintessential postmodern (including, if you can imagine, postmodern restrooms). Such pastas as lemon pepper fettuccine, penne with spinach and prosciutto, as well as thin-crusted pizzas, and veal and chicken dishes are on the upbeat menu. Get a seat by the window if you can to watch the pre-performance street parade.

Risata, 2301 Woodward, Detroit; (313) 965-9500; dinner, Wednesday-Sunday; average dinner entrée: $\$ 15$. Reservations recommended.

On the other side of the Fox, Risata is the "house restaurant" for the Second City

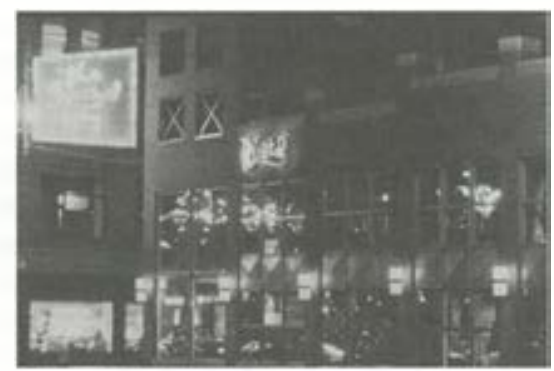

Huge portions and fun service highlight the Risata restaurant

comedy troupe. The street-level bar has its own casual menu of soup, salads, sandwiches, and pepperoni pizza at lunch and dinner, while on the second level, a more extensive bill of fare includes pastas, seafood, chicken Marsala, lamb and pork chops, and New York strip steak at dinner only. Huge portions and fun service make this a good spot to hang before or after the show.

Intermezzo, 1435 Randolph., Detroit; (313) 961-0707; lunch and dinner, Monday-Saturday; average dinner entrée: $\$ 16$. Reservations recommended

This beautiful room right next door to the new Detroit Opera House has dramatic high ceilings in a brick-walled, maple-floored loft building with great people-watching and an urban buzz. One of the few new Italian places downtown, offering the familiar list of favorites as well as seafood dishes. The bar, which is separate from the dining room, is one of the best-looking in the city and worth a stop for an after dinner drink or a set of live music. 


\section{Cultural Center}

The Cultural Center is just about ten blocks (but they're long blocks, so you'll need to take a taxi) up Woodward from the Theater District, and is home to many of Detroit's jewels: the Detroit Institute of Arts, Wayne State University, the Detroit Public Library, and the like. Happily, the Cultural Center is also home to many of the city's most lively dining experiences. You'll be in the area before and after the all-conference reception at the Museum of African American History, and you'll miss a treat if you don't stop at one of the places listed below.

Traffic Jam and Snug, $511 \mathrm{~W}$. Canfield, Detroit; (313) 831-9470; lunch and dinner daily, except for Sunday; average entrée: $\$ 11$.

A Detroit institution that's kept growing and changing through the years, but remains popular with theater and college crowds. Serves up original dishes, home-brewed beers and homemade cheeses, and fresh-baked breads in a quirky setting. There's something for everyone, from burgers, chili, and meat pies to salads and pasta with exotic names. Desserts are a specialty -try Carlotta Chocolatta ("the shameless hussy!"). You'll get a kick out of the mix of fashion from your dining partners-from Versace to Hilfiger to Salvation Army.

Union Street, 4145 Woodward, Detroit, (313) 831-3965; open for dinner daily, except Sunday; average entrée: $\$ 10$.

This good-looking speakeasy caters to a sophisticated (if talkative) crowd of urban hipsters. Armed with an extensive beer list ("life is too short for cheap beer," reminds the chalkboard), Union Street keeps 'em happy with great food from an eclectic menu offering the likes of apricot chicken strudel, mushroom medleys, and some great green eggs and ham. Expect the unexpected all the way around.

Majestic Café, 4140 Woodward, Detroit; (313) 833-0120; Junch and dinner daily; average: entrée \$10.

Right across the street from Union Street, the waycool art on the walls complements the Majestic's contemporary American and European specialties served in an open, airy setting. Try the filet mignon with both blue cheese mustard sauce and sun-dried cherry sauce. Whatever you do, even if you don't have a drink, don't miss sitting for a spell on the barstools, which are surely the most interesting chairs in the city (or maybe even the country).

Twingo's, 4710 Cass, Detroit, (313) 8323832 ; open early and late for lunch and dinner daily, except Sunday; average entrée: $\$ 7$.

Off-beat little coffeehouse and meeting place with the entrancing ambiance of, you'd swear, Paris's Left Bank. Cute salads and baguette sandwiches filled with charred red peppers, herbed chutney, and the like. You'll want to stay for hours (and you will if you snag one of the comfy couches upstairs).

Mario's, 4222 Second, Detroit; (313) 832 1616; open nightly for dinner; average entrée: \$20. Reservations recommended.

The place recently celebrated its $50^{\mathrm{th}}$ an niversary in the same spot-how many other restaurants anywhere can make that claim? so you get the feeling they know what they're doing. Generations of theater-goers have enjoyed traditional multi-course Italian meals, including all the favorites from veal Tosca and spaghetti Bolognese to shrimp scampi and chicken cacciatore. The waitstaff is professional and long-serving (and somehow charmingly rude), and the whole place is evocative of those heady pre-"heart smart" days.

\section{Handy lunch spots}

Downtown Detroit offers dozens of quick and quirky lunchtime spots, too, in case you don't have time for a big deal at dinner but want to get away from the Convention Center for a mid-day break. Here's mention of a couple that are sure to beat typical Convention Center fare.

Fiona's Tea House, 945 Beech, Detroit; (313) 967-9314; average entrée: \$12. Reservations recommended.

Fiona's garden and 19th-century brick cottage are a surprise in the midst of downtown Detroit's freeways and parking lots. Entrees are light and flowery (don't worry, they're edible flowers), the scones are freshly baked, and the desserts are beautifully crafted. It's a one-of-a-kind garden in the middle of the urban jungle.

McNally's, 1300 Porter, Detroit; (313) 963-8833; lunch daily, except Sunday; average: $\$ 5$.

A retro deli offering great sandwiches with friendly counter service. McNally's 
... if you leave town hungry, it's not because you didn't have lots of delicious choices.

serves up 49 varieties of sandwiches that are interesting and good, as well as the retro Towne Club soda and an incredibly rich, whiskey-sauced bread pudding. Not too far from historic Tiger Stadium and the offices of the Detroit News and Free Press, you can have lunch elbow-to-elbow with an ink-stained wretch who frequents the place (and who may not have ever noticed all the kitschy Farrah Fawcett lunchboxes adorning the window sills).

Evie's Tamales, 3454 Bagley, Detroit; (313) 843-5056; open for lunch daily; average entrée: $\$ 5$.

Take a quick ride out to Detroit's Mexicantown and enjoy the best tamales in the city at Evie's: steamed, corn-huskwrapped pork-and-cornmeal delights. The hot ones are really, really hot. It's a tiny place, so they'll get you in and out in a hurry.

Coney Island, 114 Lafayette, Detroit; (313) 961-7758; average "entrée": \$2.

Especially if you're tired of cutsey tea houses and want to adopt the "when in Rome" policy, then your Detroit experience is not complete without an authentic Coney Island lunch: a couple hot dogs on steamed buns, slathered in chili and chopped onions and yellow mustard, with a side of chili-cheese fries. Make a mental note before you head back to conference: pop a couple breath mints.

\section{Dearborn}

If your hotel is in neighboring Dearborn, or if you want to catch a bite before or after the conference reception at the Henry Ford Museum, you might want to consider some of Dearborn's finer establishments.

La Shish, 12918 Michigan, Dearborn; (313) 584-4477; lunch and dinner daily; average entrée: \$12. Reservations recommended.

Dearborn is a mecca for Middle Eastern restaurants, and this place is always packed with people of all persuasions speaking many different languages. The big platter of tender shish tawook-charbroiled chicken ka- bobs on a bed of perfect pilaf with a side of garlicky aioli dipping sauce-is a winner. Salads, too, are exceptional.

Dearborn Inn, 20301 Oakwood, Dearborn; (313) 271-2700; lunch and dinner daily, Sunday brunch; average entrée: $\$ 25$.

The Dearborn Inn exudes turn-of-the-century optimism, elegance, and social standing. Henry Ford built The Inn in 1931 to accommodate travelers to his Ford Airfield across the street. Entrees (and prices) are strictly late $20^{\mathrm{th}}$ century, and run the gamut, from fish (halibut and rainbow trout) to chicken and beef, and even the lonely vegetarian offering of risotto with seasonal vegetables. You'll feel pampered in the airy highceilinged Queen Anne style room.

Big Fish, 700 Town Center Dr., Dearborn: (313) 336-6350; lunch and dinner daily; average entrée: $\$ 15$.

Generally low-key but impressive, Big Fish doesn't go overboard on any food fad du jour. The mainstay is fish served any way you likegrilled, roasted, blackened, sautéed, or broiledthough there are a few beef, chicken, and pasta dishes thrown in to appease landlubbers. Plus, there's a handsome piano bar for pre- or postdinner gatherings.

B.D's Mongolian Barbeque, 22115 Michigan, Dearborn; (313) 792-9660; lunch and dinner daily; average entrée: $\$ 15$.

One of those u-cook-it places, where the patrons choose the raw ingredients from the buffet and proceed to grill it up to their specific liking, with the help of the trained and nearby professionals, naturally. If you know what you're doing, you'll start to feel like Ghengis Khan by the end of the meal.

Okay, so, that's probably enough for one conference-if you leave town hungry, it's not because you didn't have lots of delicious choices. The hospitality desk at the Convention Center will serve as an information gathering spot for these and other restaurants in the city. There, too, you can sign up for a dinner out hosted by a local librarian.

Here's hoping you have a chance to venture out a bit during the conference, where you'll discover that Detroit is a great town for fun and food, with lots more to offer than a dreary room service menu-a city full of restaurants and people who are all wishing you a delightful and tasty time during your visit. 


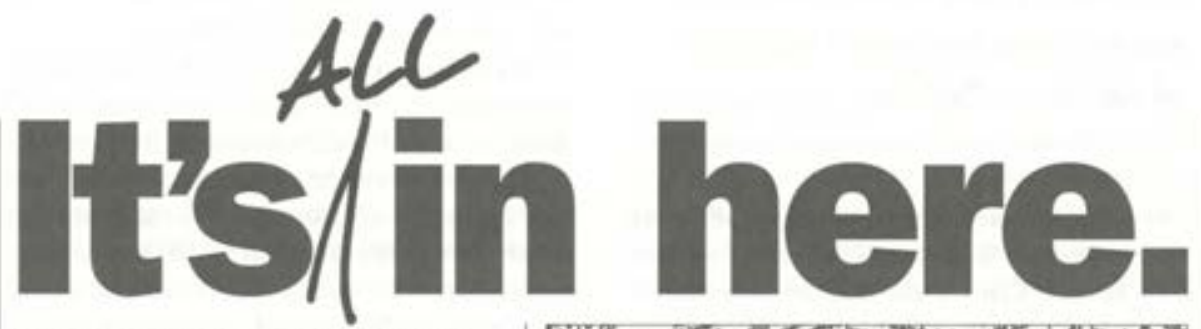

Now El covers the entire world of engineering literature - cover to cover in Ei CompendexWeb.

Search Ei CompendexWeb in Ei Village and tap into the world's largest engineering information web resource. Because we've added over one million references to the 1990s in Ei CompendexWeb already the most comprehensive interdisciplinary engineering database, and now the world's largest engineering database.

\section{More records}

Have the full backfile? You have at your fingertips over 5 million references to journal articles, conference papers and proceedings, technical reports and trade publications - with half a million more being added each year. Against the other leading databases in their fields, $\mathrm{E}$ is No. 1 in Mechanical Engineering, No.1 in Chemical Engineering, No. 1 in Civil Engineering, No.1 in Computer \& Electical Engineering, and No.1 in Engineering Management.

\section{More searching power}

Now you can count on Ei for your needs in Computers/Control, Materials, Industrial Engineering, Transportation, Structural Engineering, and more. Ei has it all.

For a free trial to Ei CompendexWeb, visit the Ei Home Page at http://www.ei.org or contact Ei at: 1 Castle Point Terrace Hoboken, NJ 07030 USA

tel 800-221-1044, fax 201-216-8532 e-mail <ei@ei.org>

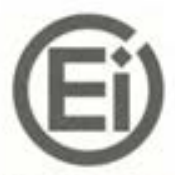

Engineering Information Inc.

$$
\begin{aligned}
& \text { Information- } \\
& \text { we've got it covered }
\end{aligned}
$$

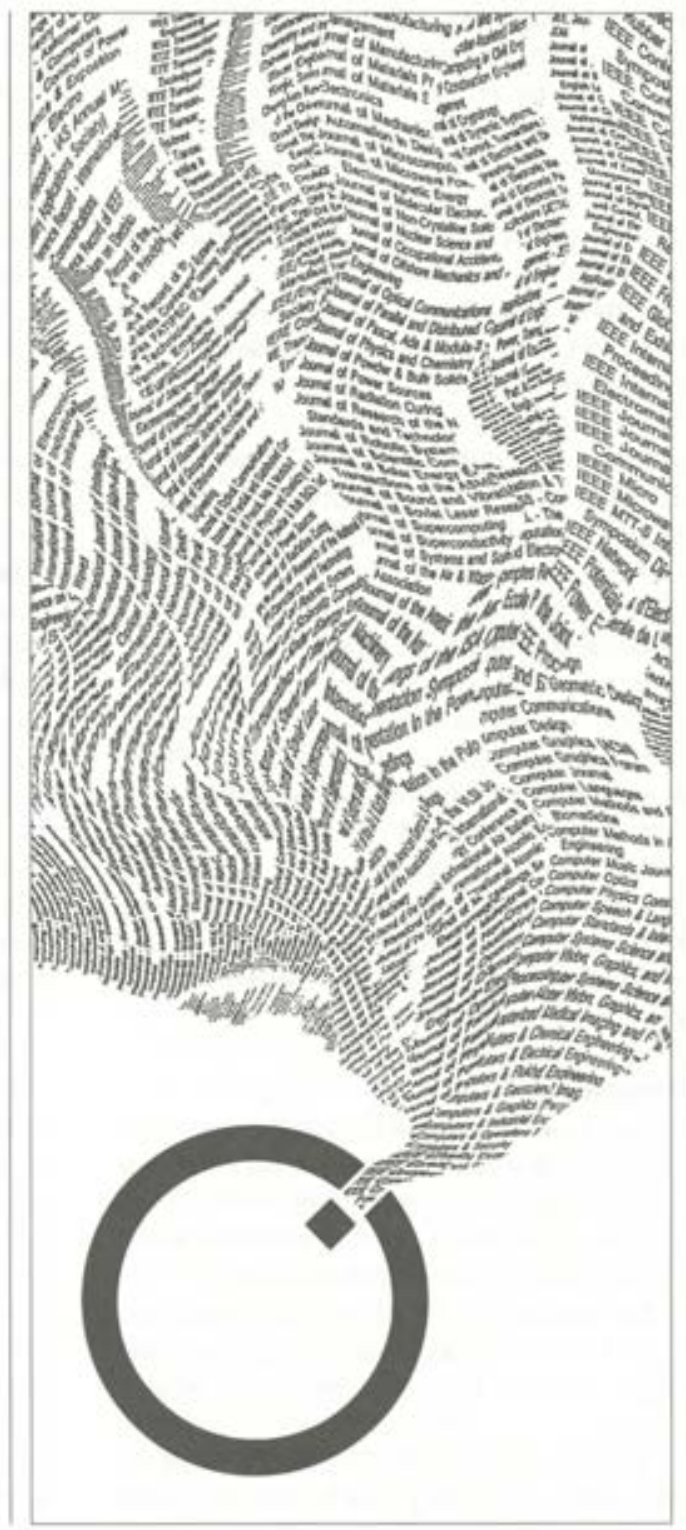




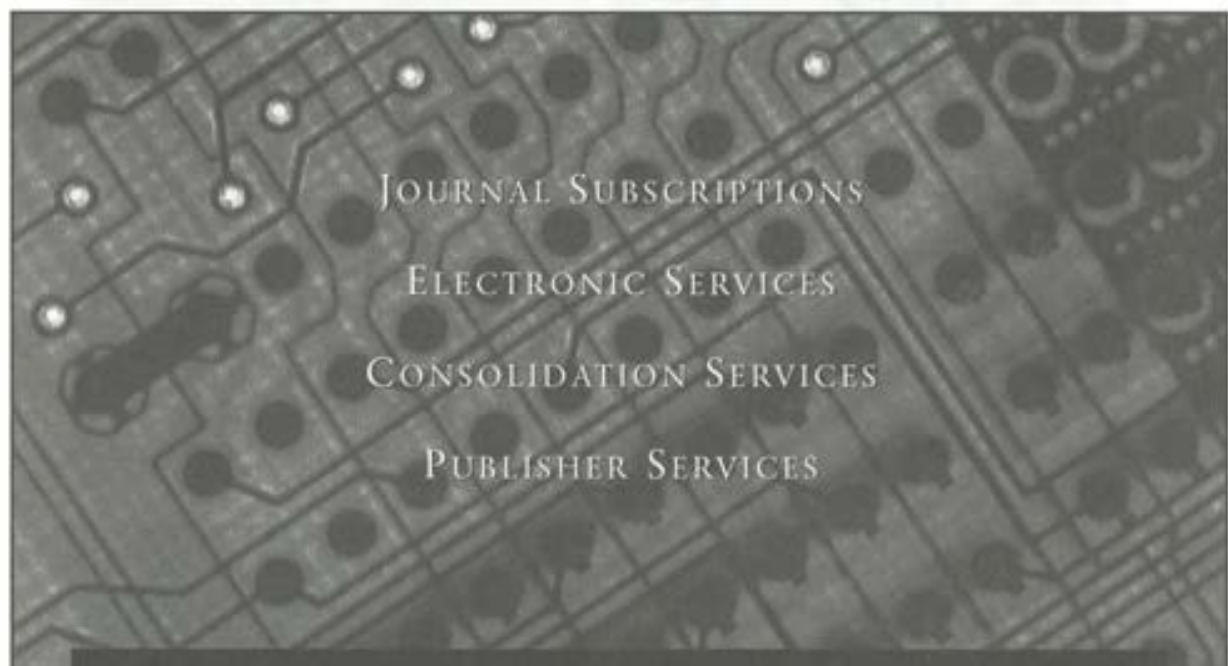

WORKING IN PARTNERSHIP

\section{BLACKWELL'S INFORMATION SERVICES}

We work in close partnership with customers and publishers to provide profucts and services designed for individual customer needs. Our electronic services are specially designed to provide a single source of electronic-subscription information to academic and research libraries.

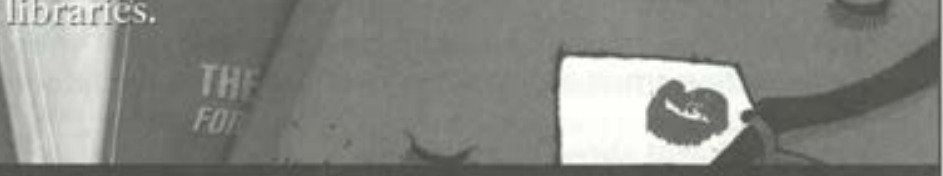

BLACKWELL'S

istoksanos

New Jerear Sulos OHice

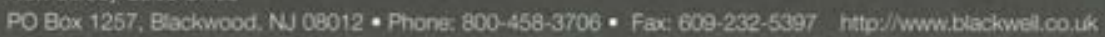



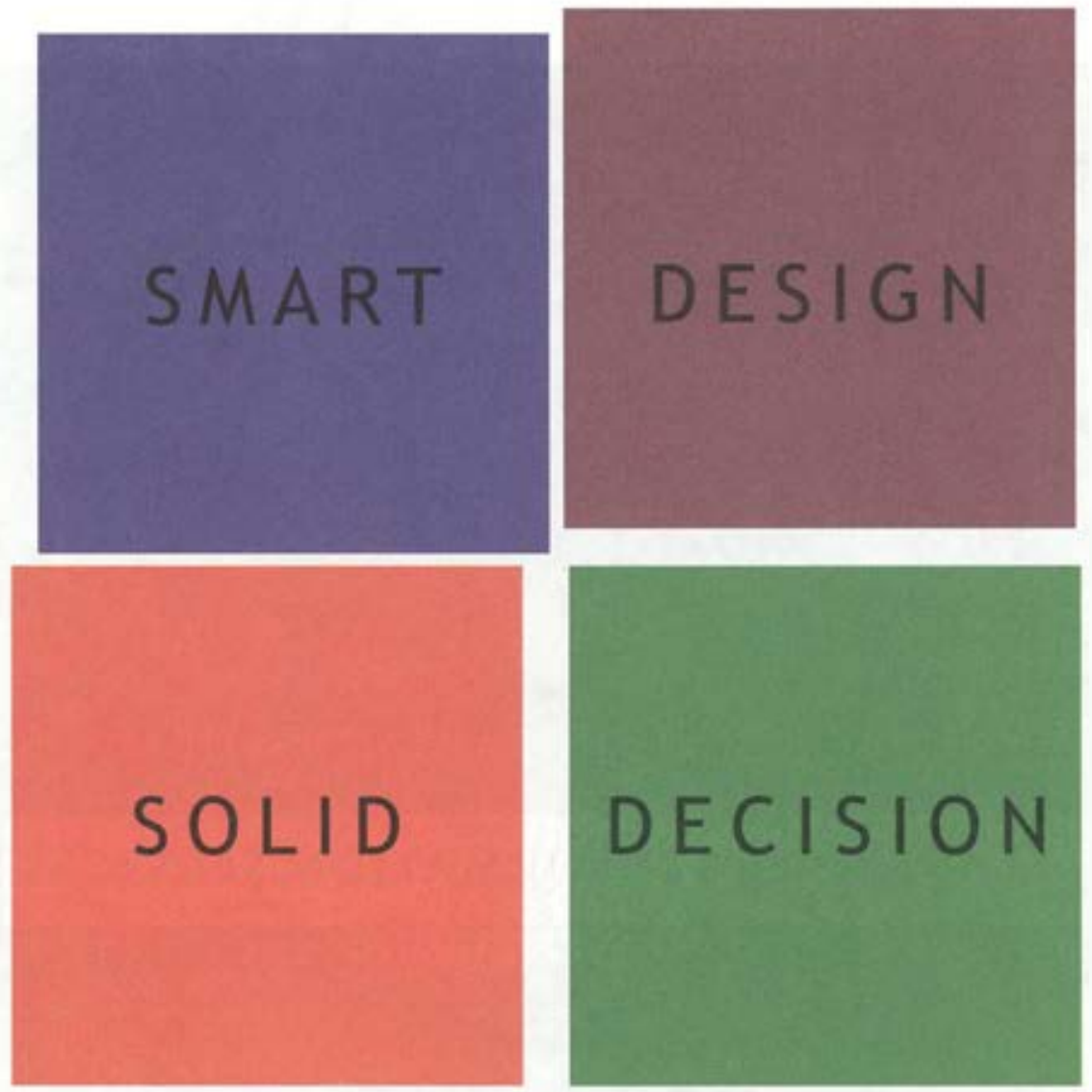

\section{What are you waiting for?}

While other companies continue to make promises about what the future will bring, Endeavor is revolutionizing library automation. Instead of rosy predictions, we've delivered real solutions to over 360 libraries worldwide with a unique combination of functionality, flexibility and stability.

You don't have to wait to make a solid decision about your library's future. By delivering smart systems, we're bringing you the future today.

Voyager is still ahead of the pack.

Visit us at www.endinfosys.com and start getting more than promises.

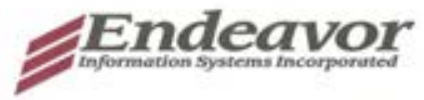

2200 E. Devon - Suite 382 • Des Plaines, IL60018-4505 • 800-762-6300 